\title{
DeVaneio sobre o sonhar acordado
}

BACHELARD, Gaston. A poética do Devaneio. Tradução de Antônio de Pádua Danesi, 5. ed. São Paulo: Editora Martins Fontes, 1988.

Há muitas questões que envolvem o universo infantil, com isso, o filósofo Gaston Bachelard (1884-1962), em sua obra "A poética do devaneio", propõe uma reflexão sobre o devaneio, ressaltando a importância desse evento não apenas nas crianças, mas também nos adultos. Portanto, o objetivo do livro é poetizar e entender que os devaneios esclarecem a alma, dão voz às imagens provenientes de sonhos intensos, em um mundo alimentado pela vontade de viver. Bachelard compreende os devaneios como o "sonhar acordado" e fantasiar a respeito de temas diversos que fazem parte do indivíduo.

O livro é dividido em cinco capítulos, sendo o primeiro: "Devaneio sobre o devaneio. O sonhador de palavras". Nessa primeira parte do livro, o filósofo cita que adota uma postura fenomenológica, ou seja, o olhar do autor está focalizado nos fenômenos que regem as vivências. Bachelard promove uma interlocução entre o psiquismo e a imaginação, sendo que os devaneios que Bachelard descreve não se separam dos valores poéticos.

O autor propõe explicar os devaneios de diferentes maneiras e perspectivas, não deixando de esclarecer a distinção entre o sonho noturno e o devaneio, que é diurno. Posteriormente, Bachelard expõe um conselho àquelas pessoas que desejam devanear, que nada mais é do que começar por ser feliz. Para o filósofo, o devaneio é a vida silenciosa dos sonhos, e é essa paz que o poeta deseja alcançar e mostrar em sua poesia.

Em seu próximo capítulo "Devaneios sobre os devaneios. Animus - Anima”, o filósofo chama a atenção para o gênero das palavras, e mostra certo desconforto com o fato de uma palavra em determinada língua ser de um gênero e a mesma palavra em outra língua ser de outro gênero. Para melhor explicação do feminino e do masculino, Bachelard usa o conceito de animus e anima, proposto por Carl Gustav Jung (1875-1961). A característica da teoria de Jung é abranger a dialética e os opostos dentro da psique, assim, o conceito de Anima não poderia afastar-se desse quesito. Anima refere-se ao elemento feminino que aparece na psique masculina, que se relaciona com:

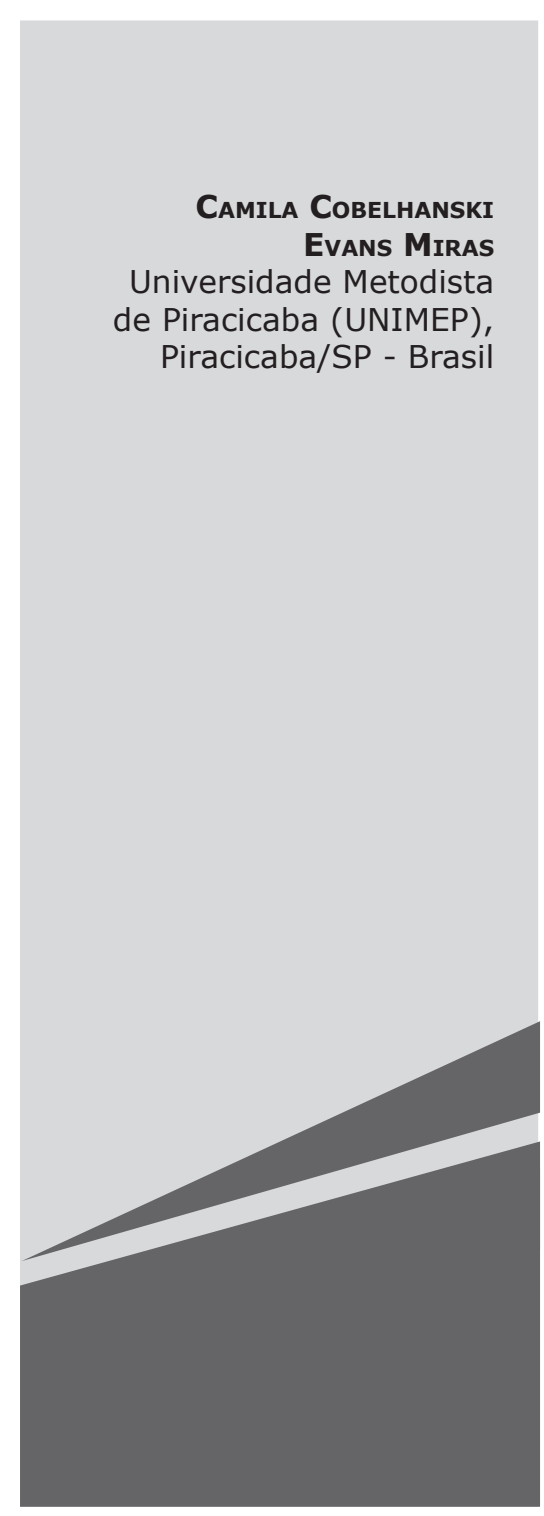


Os humores, e sentimentos instáveis, as intuições proféticas, e receptividade ao irracional, a capacidade de amar, a sensibilidade à natureza e, por fim, mas não menos importante, o relacionamento com o inconsciente (JUNG, 1964, p. 234).

Jung (1964) compreende que há dois aspectos que envolvem o conceito de Anima, o benévolo e o maléfico. "A mulher pode ser considerada uma anima letal (...). Também malévolas são as Lorelei do mito germânico, espíritos das águas cujo canto conduz os homens à morte" (p. 236).

O Animus, segundo Jung, é compreendido como o lado masculino na psique feminina. Jung (1964) destaca que "quando uma mulher anuncia tal convicção com voz forte, masculina e insistente, ou a impõe às outras pessoas por meio de cenas violentas, reconhece-se facilmente a sua masculinidade encoberta" (p. 251). Assim como a Anima, o Animus tem seu lado positivo e negativo. O negativo se manifesta quando se apresenta um grupo de criminosos, por exemplo. Já o lado positivo se relaciona com a evolução espiritual e ideias criadoras.

Jung em sua teoria aborda também aspectos do inconsciente coletivo, que nele são armazenados arquétipos desde o início da vida do homem na Terra, podendo fazer um paralelo entre os questionamentos, dúvidas e fantasias que permeiam a existência do homem, fazendo que Bachelard se identifique e expresse em sua filosofia possíveis explicações e ensinamentos acerca do assunto.

Gaston Bachelard questiona a projeção e analisa de forma clara que há animus e anima em todo ser humano dado como normal. O homem busca na mulher amada a anima que existe dentro dele. E é a partir dessas duas forças poderosas (animus e anima) que o alquimista pretende conhecer a alma do mundo. Cabe dizer que o autor pede para que o livro seja lido em anima, ou seja, de forma poética.

No terceiro capítulo, "Os devaneios voltados para a infância", Bachelard afirma que tudo que sabemos da nossa infância é resultado daquilo que nos contaram sobre ela. O devaneio na criança é o momento em que o silêncio reina em seu mundo interior, e que é capaz de esconder dos adultos o seu mundo de fantasias, também é o instante em que ela pode fantasiar a respeito do que desejar, ou seja, é o momento em que ela faz jus ao que há de melhor na infância. Nesse capítulo, o poeta tenta resgatar a fantasia, a imaginação da infância única, rica em significado, criativa e potente.

Para o filósofo, o termo correto a ser utilizado para o devaneio na criança é onirismo, podendo ser relacionado também à imaginação que segundo o filósofo é uma força, não sendo necessário saber o que é de fato.

No quarto capítulo, chamado "O cogito do sonhador", Bachelard afirma que os devaneios revelam as tentativas de individuação do homem. Além disso, pressupõe que no devaneio há uma existência de consciência. Quanto ao sonho noturno, Bachelard justifica que nessa obra não cabe estudá-lo, mas comenta que é nele que nossos fantasmas aparecem, como se o Eu se perdesse numa noite de sonhos, os aspectos do sonhador falam de maneira imperfeita, mediante símbolos. $O$ autor afirma que a partir de um 
devaneio pode surgir um sonho, e quando isso ocorre, o sonhador lembra-se apenas de seu sonho noturno.

O último capítulo da obra recebe o título de "Devaneio e Cosmos", onde o filósofo comenta que as imagens cósmicas nunca se contradizem, e que é a partir delas que o surgimento de um devaneio pode ocorrer, assim como pode acontecer de uma imagem fazer surgir outras imagens e desse modo construir um devaneio único. O devaneio cósmico é um fenômeno de solidão, é tranquilo e estável.

Bachelard comenta que os poemas caminham na direção de um fazer com o qual reencontramos aquela respiração de quando éramos crianças, quando víamos o mundo com um olhar encantador. Cada elemento cósmico é uma palavra ou uma imagem que faz a união do homem com o mundo íntimo, psíquico, certamente porque, segundo o autor, a infância do homem e do mundo são as mesmas.

"A poética do devaneio" contribui de forma significativa não apenas para os filósofos, mas para os psicólogos também, visto que é refletido em diferentes abordagens sobre o sonho noturno, distinto dos devaneios, que preenchem poucas páginas de reflexões de teorias psicológicas. Assim, a teoria de Bachelard agrega conhecimentos que podem ser bastante úteis a uma ciência que tem como objetivo conhecer o ser humano. Bachelard escreve de forma clara e convincente, além de chamar a atenção para a subjetividade dando a impressão que estamos lendo uma poesia.

Obra do século XX, no entanto faz imenso sentido e coerência nos dias de hoje. Um aspecto que vale ser ressaltado é o fato de o filósofo acreditar que o real não existe, e quem cria o real é a imaginação, assim, o limite do nosso mundo é o limite do nosso imaginário. Fazendo que o leitor reflita sobre a hipótese de que cada ser humano é um ser único em relação à compreensão do mundo, assim, o mundo subjetivo de cada pessoa se sobrepõe ao mundo objetivo. Ou seja, o mundo subjetivo cercado pelas crenças, valores e história de vida influencia o mundo objetivo que é caracterizado por abranger apenas os fatos em si.

\section{REFERÊNCIA}

JUNG, Carl Gustav. O homem e seus símbolos, 2. ed. Rio de Janeiro: Nova Fronteira, 2008.

\section{DADOS DA AUTORA}

\section{Camila Cobelhanski Evans Miras}

Graduada em Psicologia pela Universidade Metodista de Piracicaba. Piracicaba/SP - Brasil.ccemiras@gmail.com

Submetido em: 02-11-2016

Aceito em: 26-04-2017 